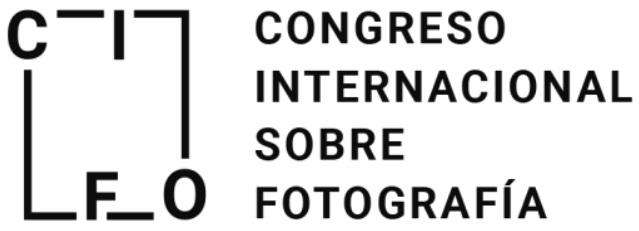

Congreso Internacional sobre Fotografía

UPV, 5 y 6 octubre 2017

Doi: http://dx.doi.org/10.4995/CIFo17.2017.6763

ISBN: 978-84-9048-604-7

\section{Imaginando los lugares e idealizando el arte a través de la fotografía e internet}

\section{Ana Martí Testón}

Universitat Politécnica de Valencia. anmartes@upv.es

\begin{abstract}
The reproduction of the cultural heritage and objects included in museums and collections has been carried out since the origins of art. But there are two key moments in the reproduction of artworks that we want to analyse and compare: the birth of photography in 1839 and the rise of digitization and the internet today. In this article we have compared the two events to analyse the need to reproduce and to communicate the works, as well as the consequences they have had in the society in both periods so that the conclusions could help us in future investigations.

Since the birth of photography, this has been considered as an ideal tool to classify the reality and establish testimonies of experiences. That nineteenth-century impulse to locate, record and control heritage is still present in our society. Museums are digitizing their collections compulsively with the intention of making them more accessible. However, these initiatives are far from demonstrating that they serve as a real incentive to increase society's interest in this heritage.
\end{abstract}

\section{Keywords:}

Art reproduction, Photography, idealisation, heritage, digitization, museums, internet

\footnotetext{
Resumen

La reproducción del patrimonio cultural y de los objetos incluidos en los museos y las colecciones se ha venido realizando desde los orígenes del arte. Pero existen dos momentos clave en la reproducción de obras de arte que queremos analizar y comparar: el nacimiento de la fotografía en 1839 y el auge de la digitalización e internet en la actualidad. En este artículo hemos comparado los dos acontecimientos para analizar la necesidad de reproducir las obras y comunicarlas, así como las consecuencias que han tenido en la sociedad en ambos períodos para que las conclusiones nos ayuden en futuras investigaciones.
}

Desde el nacimiento de la fotografía, ésta ha sido considerada como una herramienta ideal para clasificar la realidad y establecer testimonios de las experiencias vividas. Aquel impulso 
decimonónico de localizar, registrar y controlar el patrimonio sigue presente en nuestra sociedad. Los museos están digitalizando sus colecciones compulsivamente con la intención de hacerlas más accesibles. Sin embargo, estas iniciativas siguen lejos de demostrar que sirvan por sí mismas de incentivo real para aumentar el interés de la sociedad por este patrimonio.

\section{Palabras clave:}

Reproducciones de arte, fotografia, idealización, patrimonio cultural, digitalización, museos, internet.

\section{Introducción: El auge de la reproducción del patrimonio cultural}

Una de las principales limitaciones respecto al acceso al patrimonio cultural por parte de la sociedad es que las diferentes obras, objetos, lugares o gentes, se encuentran distribuidos por la geografía, y para acceder a ellos (ej. con la intención de estudio, educación, y / o disfrute) los interesados deben viajar, lo que requiere invertir tiempo y dinero, siendo estos dos obstáculos adicionales que limitan el acceso a dicho patrimonio.

Con la intención de mejorar la conservación y difusión de estas obras, muchas instituciones han reproducido una copia de los objetos que muestran a las personas que por alguno de los motivos ya citados no podían disfrutar de ellos. Las técnicas utilizadas para reproducir estas obras han ido evolucionando a lo largo del tiempo, puesto que el arte ha sido susceptible de ser reproducido prácticamente desde sus orígenes. Pero existen dos momentos clave en la reproducción de obras de arte: el nacimiento de la fotografía en 1839 y el auge de la digitalización e internet en la actualidad. En este artículo pretendemos comparar los dos acontecimientos para extraer conclusiones que nos ayuden en futuras investigaciones.

\subsection{Objetivos de la investigación}

Por lo tanto, uno de los principales objetivos de esta investigación es analizar el impacto que ha supuesto la reproducción de obras de arte en los dos períodos concretos: en el nacimiento de la fotografía en el S.XIX y el auge de la digitalización e internet en el S.XXI.

Además, queremos entender la necesidad de reproducir las obras y comunicarlas en los dos periodos y las consecuencias que han tenido en la sociedad.

\section{La fotografía como herramienta para reproducir el patrimonio cultural}

\subsection{La fidelidad respecto a lo reproducido}

Ya en la prehistoria, las pinturas rupestres eran reproducidas y copiadas, y en el Quattrocento, así como en el Barroco, Neoclásico o Romántico, las obras de los grandes maestros eran imitadas por los discípulos con la intención de mejorar la técnica o incluso difundir sus obras. 
Pero el nacimiento de la fotografía en 1839 supuso una importante revolución en este campo, así como en otros, pues muchos científicos, exploradores y apasionados del nuevo invento vislumbraron una nueva oportunidad para reproducir las obras y presentarlas a un público más amplio de un modo mucho más instantáneo, mejorando notablemente los resultados de la técnica que antecedía a la fotografía: el grabado.

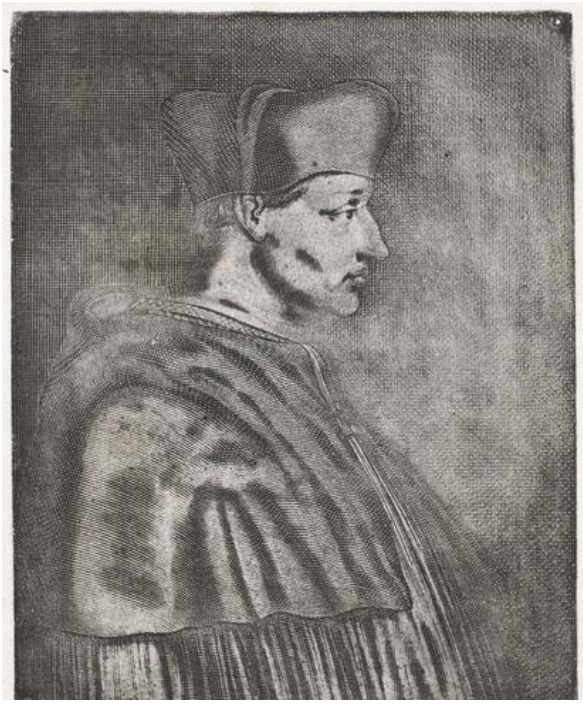

Imagen 1. Heliograbado realizado por Joseph Nicéphore Niepce en 1826 Copia del grabado de Isaac Briot de 1650 con el retrato del Cardenal Ambroise. $22.8 \times 13 \mathrm{~cm}$, Museo de Orsay, Paris.

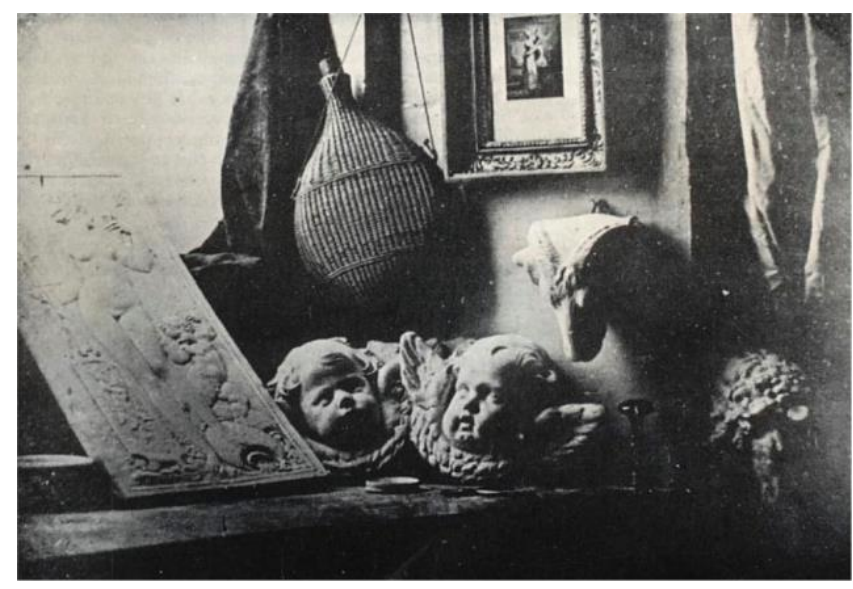

Imagen 2. El taller de Daguerre, Daguerrotipo realizado por Daguerre en 1837. Société française de photographie, París.

Desde sus orígenes, una de las tareas primordiales de la nueva invención de Daguerre fue la reproducción de obras de arte. Tanto es así, que la invención fue alabada incluso por sus detractores, pues la fotografía permitía la reproducción fiel del original (Dominique de Font-Réaulx, Joëlle Bolloch, 2006). La fotografía pretendía acercarse a las bellas artes y por ello copiaba de la pintura los encuadres y temas: retrato, bodegón, paisaje, etc. 
Los daguerrotipos reproducían las obras de arte con una nitidez que ha sido difícil de superar por otras técnicas fotográficas posteriores, llegando a realizar fotografías estereoscópicas que permitían una reproducción tridimensional de las esculturas.

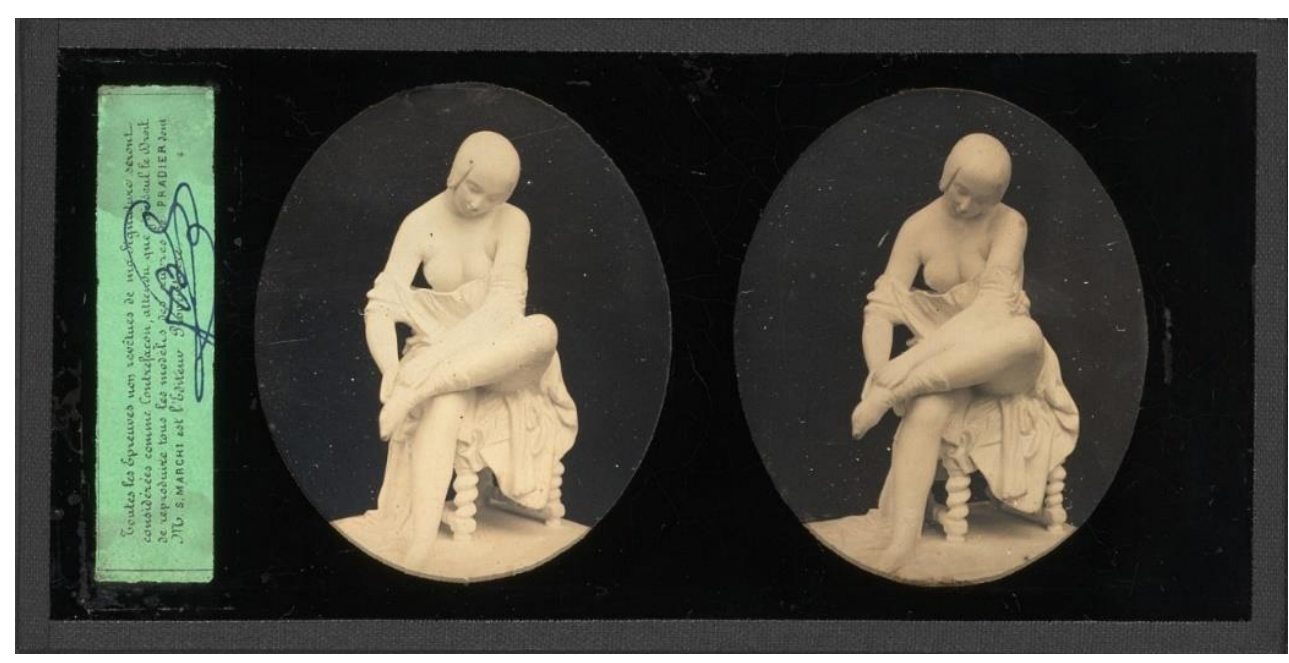

Imagen 3. Mujer con medias, escultura de James Pradier, Daguerrotipo estereoscópico realizado entre 1851-1852, $65 x 55 \mathrm{~mm}$, Biblioteca Nacional de Francia.

\subsection{La masificación de las copias del patrimonio}

A partir de 1841 William Talbot inventa el negativo fotográfico del que se podían realizar múltiples copias y posteriormente, cerca de 1860, mejoraron las técnicas de reproducción de imágenes gracias a la industrialización del proceso. Las copias de las obras se multiplicaron y se imprimieron reproducciones de estas en tarjetas de visita, álbumes coleccionables y pequeñas postales, produciendo un fenómeno de masas en sí, tanto por su extensa difusión, como por su uso como vehículo de socialización y objeto de distracción. Además, ese potencial de reproducción masiva le otorgó un carácter de mercancía, como señalarían Adorno y Horkheimer, dada su estandarización y estereotipación de los lugares que se representaban y el modo en que se hacía (Colorado Nates, 2013), desarrollando a partir de entonces un papel crucial en la reproducción, circulación y el conocimiento de las obras de arte y lugares que se reproducían. 


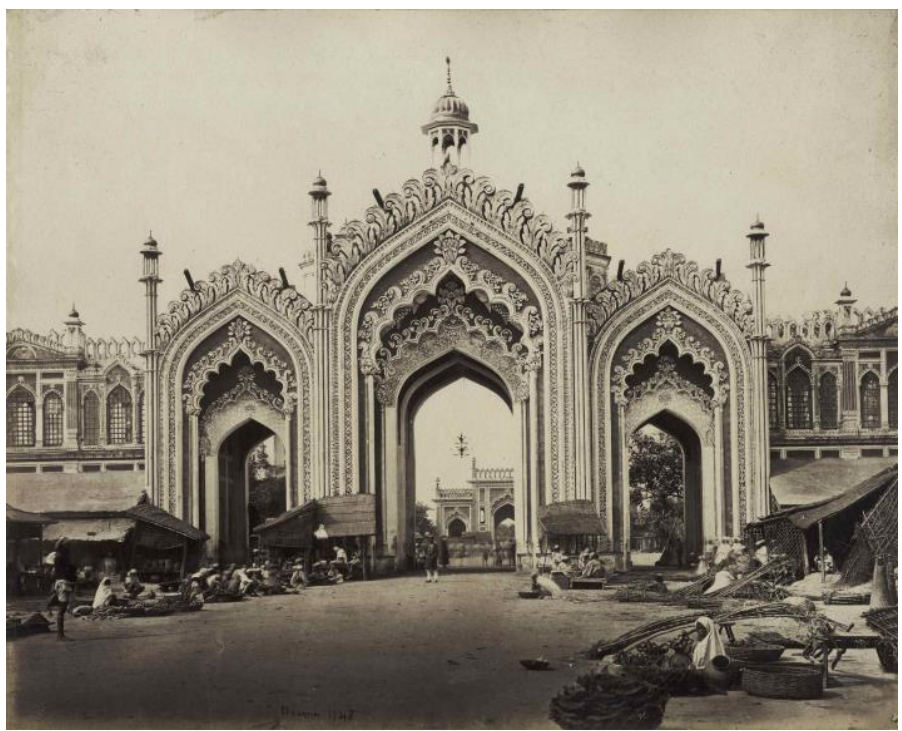

Imagen 4. La puerta de Husainabad, Lucknow, India. Samuel Bourne, 1865, Fotografia a la Albumina.

La fotografía fue además una herramienta que utilizaron los pintores para desarrollar sus obras y dada su cualidad para reproducir fielmente la realidad, desde entonces cambió radicalmente el modo en que estos pintaban, pues ya no era necesario copiar la realidad. Como consecuencia, los artistas se centraron en la propia expresividad de los medios, además de estar influidos por los nuevos puntos de vista y encuadres que ofrecía la fotografía. Recordaremos como en 1855 la fotografía fue desplazada del Palacio de Bellas Artes al Palacio de la industria junto a otros inventos. $\mathrm{Y}$ ese mismo año, el pintor Gustavo Couvert fue rechazado del salón y expuso su obra "El taller del pintor" en una exposición que tituló "Realisme" donde criticaba entre otras cosas si la finalidad del arte era la reproducción exacta de la realidad (Rafael Levenfeld, Valentín Vallhonrat, 2015).

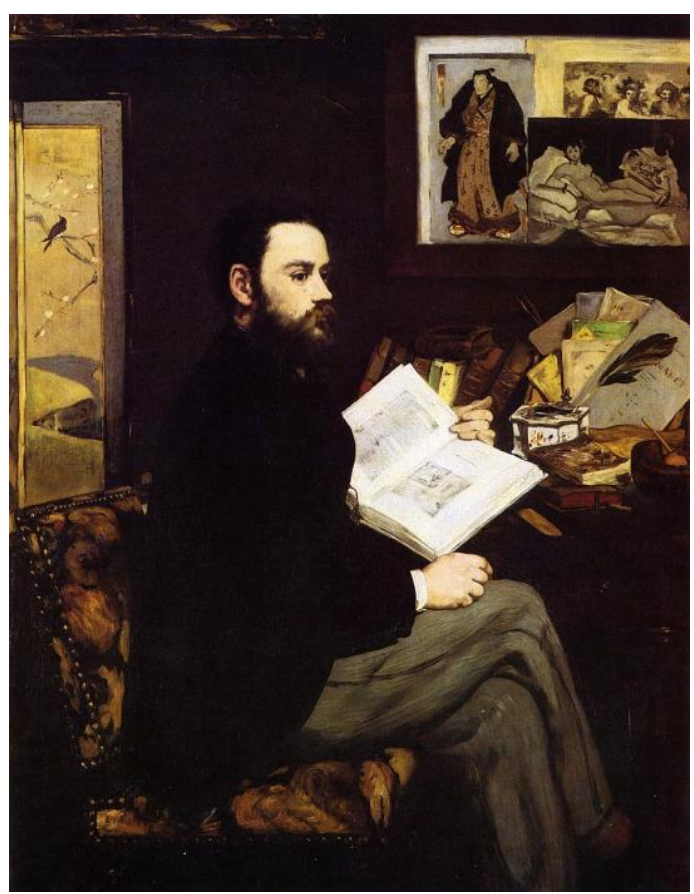

Imagen 5. Eduard Manet, Retrato de Émile Zola, 1868 Óleo sobre lienzo $146,3 \mathrm{~cm} \times 114 \mathrm{~cm}$ Museo de Orsay, París. 


\section{El auge del patrimonio cultural y la democratización de la cultura}

A mediados del siglo XIX, Europa vivió un auge romántico ensalzando el interés por el patrimonio cultural y exótico. Como consecuencia, se crearon los primeros museos nacidos a causa de la expansión colonial decimonónica que combinaba la curiosidad por lo extraño y el desarrollo del espíritu científico que se vio animado por las teorías del evolucionismo (Hernández, 2005: 232).

Por ello, no es casualidad que surgiera al mismo tiempo el interés por el patrimonio cultural, el nacimiento de la fotografía y el auge por la reproducción de las obras y la representación de los lugares exóticos. Según Antonio Ariño, en esta época, podemos reconocer la existencia de un movimiento global de patrimonialización de la cultura que "se hace evidente en el descentramiento de occidente, tras el fin del colonialismo, y el desafío correlativo lanzado por las nuevas naciones, cuando reclaman la restitución de sus patrimonios expoliados" (Ariño, 2010). Precisamente, algunos de los primeros fotógrafos, especialmente los Calotipistas, estaban atraídos por la literatura romántica y los libros de viajes y realizaron gran cantidad de imágenes en las que representaban los lugares lejanos.

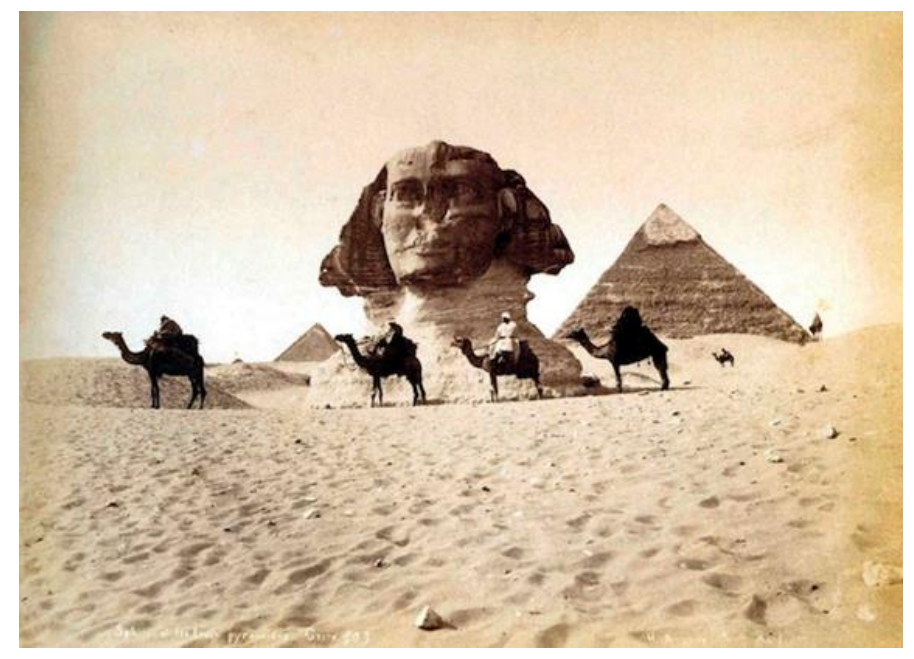

Imagen 6. Fotografia de Maxime Du Camp 1849

Du Camp fue uno de los primeros reporteros de viajes.

Según Ariño, esta fiebre de nostalgia y conservacionismo que subyace en las prácticas patrimonializadoras, suele ignorar en qué medida conservar es transformar y fetichizar. (Ariño, 2010). Y ciertamente llegados a este punto nos preguntamos si realmente los lugares y obras reproducidos eran fieles a la realidad que representaban, puesto que en todo proceso de construcción de identidades se produce una interpretación y selección (mitificación y sacralización) de lo representado, que otorga sentido a la nueva identidad (Hernández, 2005). Las fotografías de las postales de las carte de visit ya comentadas, que representaban la reproducción de las obras de los museos y de los trajes típicos de cada región contribuyen a perpetuar esas identidades, "La larga vida de los estereotipos y su proliferación indican que estos ejemplos de fantasía colectiva respondían a los deseos de una sociedad por distinguirse" (Bourdieu, 2003).

\subsection{La idealización del patrimonio}

Esa dimensión identitaria del patrimonio perseguía representar una identidad y una imagen de una práctica cultural idealizada. Con la intención de remarcar y reforzar la cultura propia se buscaba la comparación con las culturas ajenas y lejanas, y como resultado, las escenas se idealizaron según la mirada del fotógrafo extranjero. Según Peter Burke, "La importancia de la distancia social y cultural resulta especialmente clara en aquellos 
casos en los que el fotógrafo es ajeno a la cultura que retrata, generando estereotipos de los otros" ... "La invención consciente o inconsciente de la otra cultura opuesta a la propia" (Burke, 2001). "Tanto si son pinturas cómo si se trata de fotografías, lo que recogen los retratos no es tanto la realidad social, cuanto las ilusiones sociales, no tanto la vida corriente, cuanto una representación especial de ella" (Burke, 2001).

Según Ariño, "el patrimonio cultural ha estado vinculado siempre a unas bases sociales, y mediante esta, a una comunidad imaginada. En los orígenes, la idea era la apropiación de los tesoros aristocráticos por el estadonación, y la creación por éste de museos nacionales para expresar su continuidad histórica, su identidad y su proyección futura" (Ariño, 2010). Somos conscientes de como los museos y otras instituciones culturales han custodiado objetos valiosos que a su vez han difundido para mejorar tanto la imagen de esta institución como el estado o nación que representan, facilitando el acceso a las obras que antes pertenecían a una colección privada. En el último siglo, se han reproducido una gran cantidad de obras de arte y se han comercializado en forma de calendarios, ilustraciones para libros de texto, postales, etc... Favoreciendo de este modo la idealización del patrimonio cultural.

\subsection{Las teorías de Walter Benjamín y el aura de la obra de arte}

Tal fue el impacto de la reproducción de obras en la sociedad de principios del siglo XX, que, en 1936, el filósofo Walter Benjamín escribió uno de los textos más relevantes de estética: "La obra de arte en la era de su reproductibilidad técnica". Alarmado por la repercusión que el cine y la fotografía tuvieron en el campo del arte, se preocupó por las transformaciones que en ese momento se estaban desarrollando en las formas de expresión artística y en la propia naturaleza de la obra arte. Según sus conclusiones, estas transformaciones anticipaban otras de carácter político y social. Como ya es bien conocido, Benjamín argumenta que la reproducción técnica de las obras de arte destruye su "aura", quitándoles así algunos atributos que hacen que esa obra original adquiera el valor social que le corresponde (Benjamin, 2010).

Durante el siglo XX se ha intentado acercar el arte a la sociedad con el afán de democratizar la cultura y hacerla más accesible a las clases más bajas. Y si bien es cierto que se han construido gran cantidad de museos y se han reproducido muchas de las obras y monumentos en distintos soportes (como por ejemplo los libros de texto), parece que esta democratización no se ha realizado con la intención de mejorar la cultura general de la sociedad, sino que pareciera que la masiva comunicación de determinados bienes culturales en detrimento de otros ha reforzado determinados iconos culturales que han adquirido por ello una nueva "aura" gracias a su reproductibilidad. Si bien perdieron su "aura" al ser reproducciones y copias de originales, la han vuelto a ganar a costa de insistir en la comunicación y divulgación de determinadas obras. Según Bourdieu, la transmisión escolar cumple siempre una función de legitimación, "aunque no sea más que por la consagración que confiere a las obras que constituye como dignas de ser admiradas por el hecho de transmitirlas y contribuye por ello a definir la jerarquía de los bienes culturales y los grados de legitimidad" (P. Bourdieu; A. Darbel, 2004).

Según Néstor García y Agustín Santana es importante tener en cuenta los efectos negativos y las consecuencias que puede causar la sobreexplotación del patrimonio; "El desarrollo urbanístico y el turismo entendido como un fenómeno de masas puede alterar las funciones y los significados de los referentes patrimoniales. El reducir el patrimonio a mero producto de consumo, la idealización de la realidad, el patrimonio-ficción, representado para los otros, o el convertir las zonas deprimidas social y económicamente en reservas naturales y "culturales" favorecen la despatrimonialización" (Marcos Arévalo, 2010).

En el siglo XXI, hemos experimentado una nueva revolución en la comunicación de las obras de arte y su reproductibilidad que ha sido entendida por muchos como una nueva vía de democratización de la cultura. Acercando las obras de arte y el conocimiento a aquellas personas que no disponen de los medios que hemos 
Imaginando los lugares e idealizando el arte a través de la fotografía e internet

comentado al inicio del texto, como el tiempo o dinero, para desplazarse a los museos o lugares en los que se encuentra ese patrimonio cultural.

\section{La revolución digital}

\subsection{Una nueva revolución tecnológica en la reproducción de las obras.}

Desde 2008, la mayoría de museos y archivos han gastado y están gastando, grandes cantidades de dinero y tiempo en digitalizar sus colecciones con la intención de hacerlas más accesibles al público en general (European Commission, 2015) (Natasha Stroeker, René Vogels, 2014). Grandes proyectos, como Google Art Project o Europeana pretenden acercar la cultura a la sociedad eliminando determinadas barreras físicas a través de internet (Poll, 2010).

Las tecnologías digitales han permitido a los museos llegar a audiencias de todo el mundo a una velocidad hasta ahora impensable. Las colecciones digitalizadas y mostradas en internet nos permiten, además, mostrar al público online el $80 \%$ de los tesoros que se encuentran ocultos en los almacenes, custodiados allí por cuestiones de conservación o limitaciones del espacio expositivo.

En efecto, en los últimos años se han desarrollado algunas técnicas de reproducción de obras de arte que hace unos años habríamos pensado imposibles: la realidad aumentada posibilita la incorporación de datos digitales sobre el espacio real y permite, por ejemplo, la reconstrucción de unas ruinas en un centro arqueológico para una mejor comprensión de ese patrimonio. Se han desarrollado escáneres láser que permiten digitalizar esculturas y objetos obteniendo millones de puntos de resolución. Podemos crear objetos virtuales en 3D y mostrar el interior de las piezas que se tendrían que exponer cerradas. Se han escaneado pinturas con una resolución tan alta, que cuando aumentamos el zoom podemos ver detalles que hasta el momento eran imperceptibles para el ojo humano.

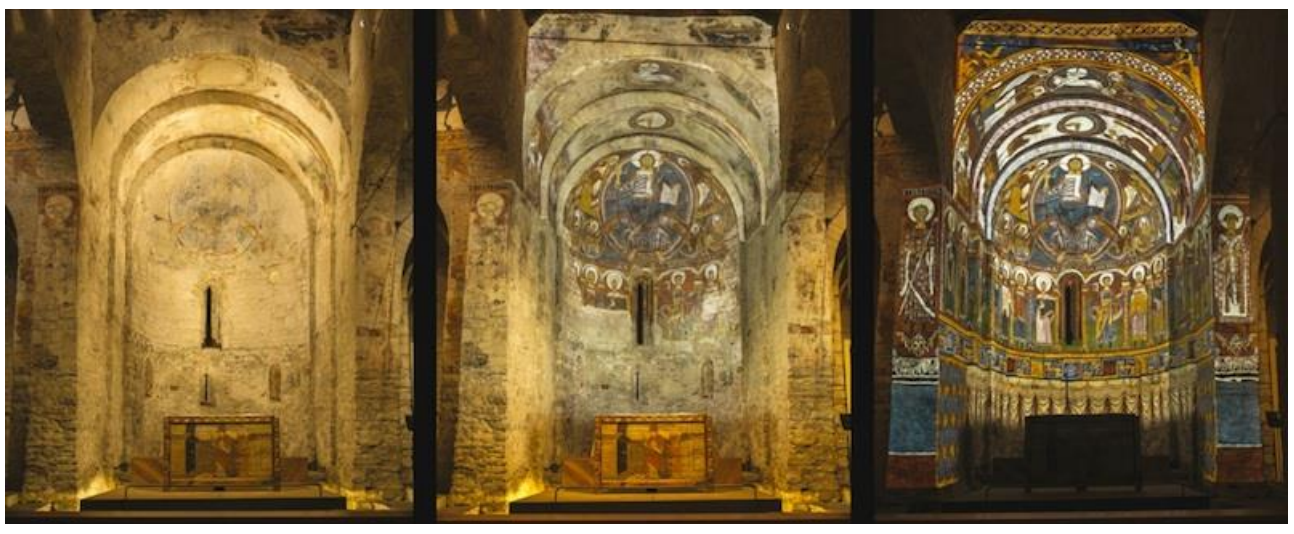

Imagen 7. Video Mapping de Sant Climent de Taüll

\subsection{Un nuevo intento de democratización de la cultura}

Las iniciativas que facilitan el acceso online a reproducciones de los objetos museables, siguen estando lejos de demostrar que sirvan por sí mismas de incentivo real para aumentar el interés de la sociedad por su patrimonio. De hecho, algunos estudios recientes muestran el poco uso de estas colecciones digitalizadas y, por lo general, el poco tiempo dedicado en cada una de ellas (Villaespesa, 2014).

Estos avances siguen siendo insuficientes para garantizar un acceso democrático a los contenidos, puesto que no sólo es cuestión de estar en Internet, de ser accesible en cualquier momento y desde cualquier lugar, sino de 
desarrollar mecanismos que incentiven la curiosidad de la sociedad por este tipo de contenidos frete a la feroz competencia de muchos otros también accesibles desde internet.

En esta línea, algunos museos han optado por basar su estrategia digital en salir del espacio expositivo del museo y colgar las copias digitales y animadas en lugares públicos como el metro o los aeropuertos en un nuevo intento de acercar el arte a la sociedad. Pero resulta complicado que estas acciones obtengan el resultado deseado, pues para democratizar la cultura hace falta algo más que la repetición y sobre abundancia de las imágenes ya idealizadas.

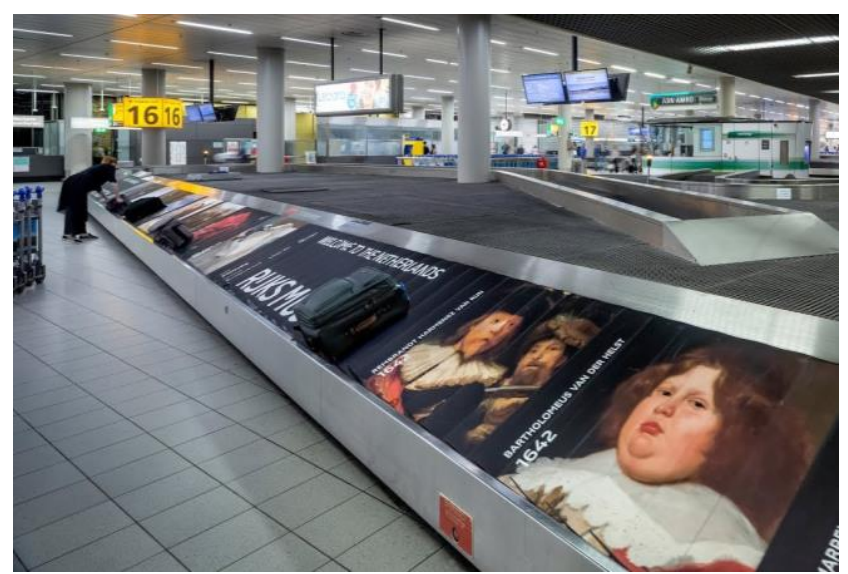

Imagen 8. Ejemplo cinta transportadora con reproducciones de obras del Rijksmuseum en el aeropuerto de Schiphol, septiembre 2017.

Según el sociólogo Bourdieu, la frecuentación de los museos obedece a una lógica de la comunicación en la que el museo propone información que se dirige a todos los sujetos de la sociedad, pero que solo adquiere sentido y valor para aquellas personas que son capaces de descifrarla y disfrutarla (P. Bourdieu; A. Darbel, 2004).

Los principales predictores demográficos a la hora de determinar la participación cultural siguen siendo el nivel educativo y los antecedentes familiares (European Agenda for Future, 2012); La pretendida democratización de la cultura deberá pasar por lo tanto por la integración de nuevos perfiles, y evitar que, como hasta ahora, el perfil de las audiencias de los museos online presente la misma composición social que las de los museos físicos tradicionales. El sentimiento de disociación con el arte (o la cultura en general), la falta de comprensión de las obras y la competitividad con otras actividades de ocio y tiempo libre, son las principales barreras que nos encontramos hoy en día a la hora de acceder a la cultura, derivadas todas ellas de las desigualdades sociales, educativas y de hábitos (European Agenda for Future, 2012).

En este contexto, el encuentro con la obra digitalizada debe permitir algo más que su pura representación visual en una pantalla de ordenador o móvil. Pero una gran mayoría de las colecciones online de los museos que hemos investigado, están diseñadas para ser utilizadas por especialistas, con estructuras de búsqueda complejas que presuponen que los visitantes saben lo que quieren encontrar. Lamentablemente, muchos ciudadanos no tienen la base cultural o la experiencia suficiente para explorar estas bases de datos del mismo modo en que lo hacen los expertos y como consecuencia, se desmotivan. 

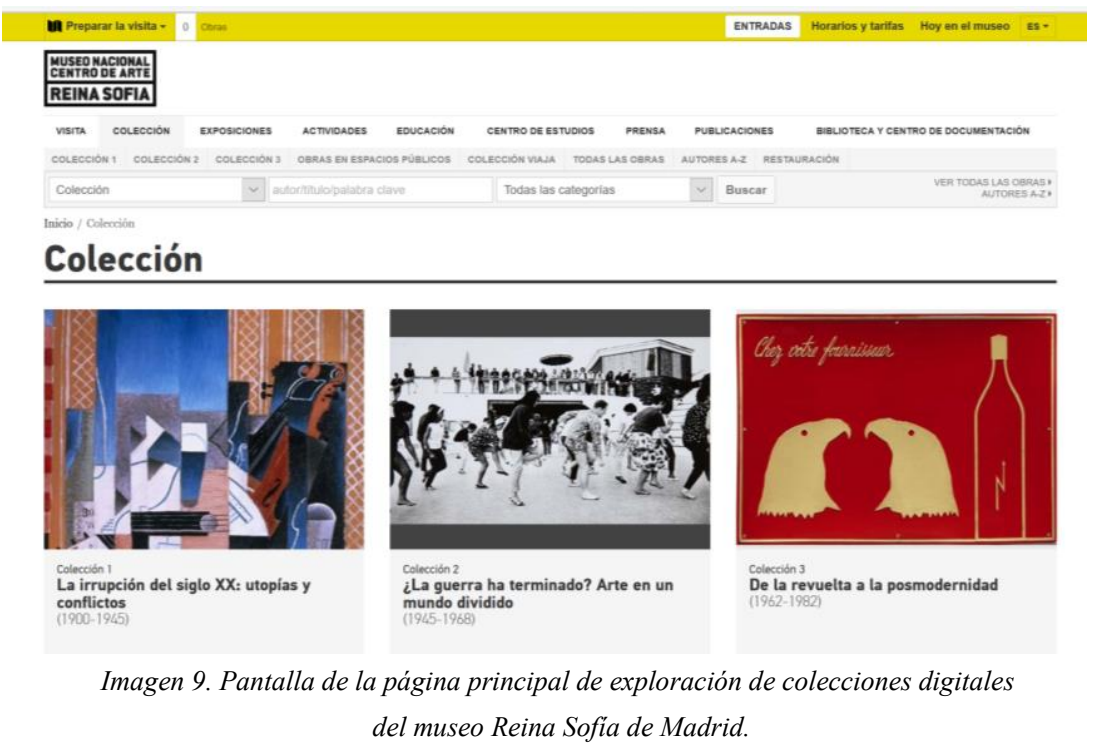

Durante los dos últimos años desde nuestro grupo de investigación hemos realizado algunas experiencias en las que utilizamos la realidad aumentada en el contexto expositivo real y virtual utilizando técnicas de visualización de obras interactivas que proceden entre otros del mundo de los videojuegos. En esta línea, también hemos mejorado la narratividad vinculada a las imágenes para que el story telling relacionado con las reproducciones de las obras incite a continuar explorando y aprendiendo.

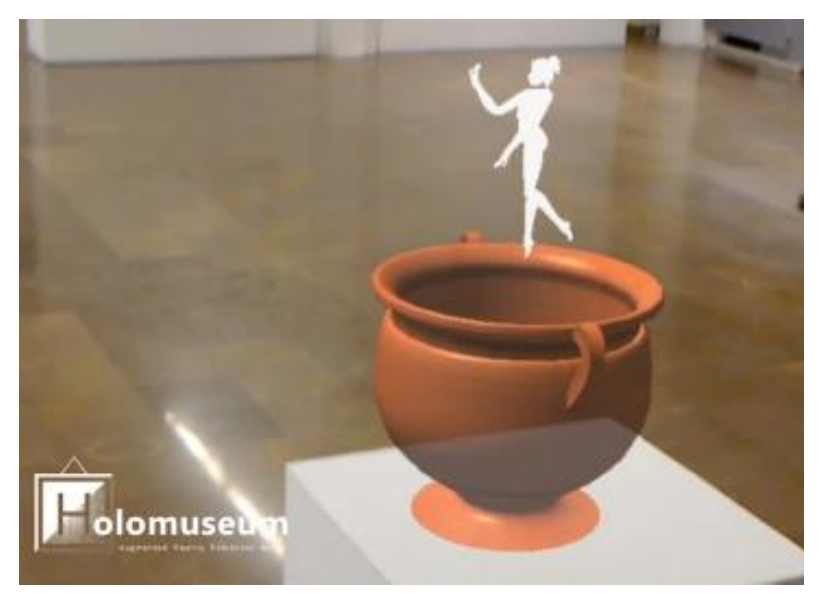

Imagen 10. Ejemplos de algunos de los desarrollos que hemos realizado en 2017. 


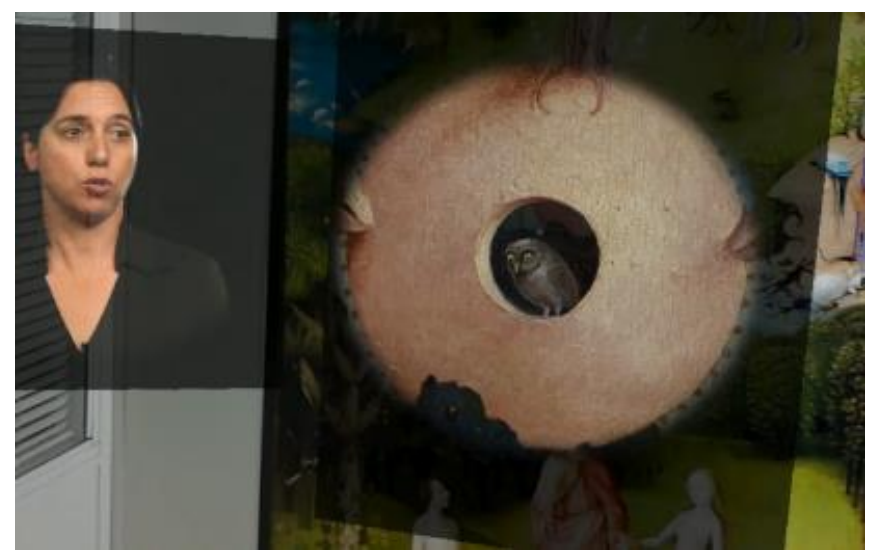

Imagen 11. Ejemplos de algunos de los desarrollos que hemos realizado en 2017.

\section{Conclusión}

El patrimonio cultural tiene un gran potencial comunicador y los museos son considerados lugares ideales donde contar historias y provocar el diálogo entre los visitantes y expertos con el objetivo de crear y transmitir conocimiento. En la actualidad, en lo referente a la reproducción de las obras mediante las tecnologías más avanzadas, podemos comprobar que este potencial comunicador se ve disminuido porque: por un lado, carecemos del objeto real y de su "aura", y por otro, no se utiliza ninguna estrategia que motive una exploración.

La tecnología, por sí misma, no es capaz de dar vida a los objetos virtuales, y por este motivo resulta fundamental desarrollar técnicas que inciten el interés en estos objetos. Pero hasta el momento, los ejemplos que encontramos nos indican que se ha hecho todo lo contrario: se muestran las imágenes de las obras desvinculadas unas de otras sin ningún tipo de narrativa que incite a explorarlas, sino que por la mera repetición se genera un discurso cerrado que no contribuye más que a idealizar este patrimonio.

Todavía hoy algunos de los argumentos de Walter Benjamín siguen siendo relevantes, especialmente en lo referente a la priorización del acto de ver, el aumento de la velocidad a través de la cual se procesa la imagen, o el hecho de que la imagen técnicamente reproducible está descontextualizada de la realidad en la que se creó (Cuadra Á. ).

La fotografía fue para Benjamín una tecnología verdaderamente revolucionaria de la reproducción, que se acercaba a una herramienta política. Pero en los tiempos de la reproductibilidad técnica digital, podemos considerar que la obra de arte se ha tornado en un mero significante, debido a la sobre abundancia de imágenes se ha convertido en una mercancía de la información y la diversión. 
Imaginando los lugares e idealizando el arte a través de la fotografía e internet

\section{Referencias}

Ariño, A. (2010). Prácticas culturales en España desde los 60 hasta la actualidad. Barcelona: Ariel, Planeta.

Imaginando los lugares e idealizando el arte a través de la fotografía e internet

Benjamin, W. (2010). La obra de arte en la época de su reproductibilidad técnica. Casimiro Libros.

Bourdieu, P. (2003). Un arte medio . Barcelona: Gustavo Gili.

Burke, P. (2001). Visto y no Visto. El uso de la imágen cómo documento histórico. Barcelona: Crítica.

Colorado Nates, Ó. (14 de septiembre de 2013). oscarenfotos.com. Recuperado el 10 de septiembre de 2017, de https://oscarenfotos.com/2013/09/14/la-fotografia-como-fenomeno-de-masas/\#_edn7

Cuadra, A. (2006). La obra de arte en la epoca de su hiperreproducibilidad digital. Re-Presentaciones, Periodismo, Comunicación y Sociedad(2), 31-46.

Cuadra, Á. (s.f.). La obra de arte en la época de su hiperreproductibilidad digital. Torre de Babel Ediciones.

Directorate General for education and culture. (2013). CULTURAL ACCESS AND PARTICIPATION REPORT, Special Eurobarometer 399. European Commission.

Dominique de Font-Réaulx, Joëlle Bolloch. (24 de junio de 2006). Art Works And Their Photographic Reproduction. París: Musée d'Orsay.

European Agenda for Future. (2012). Policies and good practices in the public arts and cultural institutions to promote better access to and wider participation. European Union.

European Commission. (2015, November 16). Member States progress reports for 2013-2015 on the implementation of the 2011 Recommendation on digitisation, online accessibility and digital preservation. Retrieved December 20, 2015, from https://ec.europa.eu/digital-agenda/en/news/2015national-reports-digital-preservation

Jameson, F. (2010). Reflexiones sobre la postmodernidad. Madrid: Abada.

Marcos Arévalo, J. (2010). El patrimonio como representación colectiva. La intangibilidad de los bienes culturales. Gazeta de antropología, 26(1).

Natasha Stroeker, René Vogels. (January de 2014). Survey Report on Digitisation in European Cultural Heritage Institutions 201 Obtenido de http://www.enumerate.eu/fileadmin/ENUMERATE/documents/ENUMERATE-Digitisation-Survey2014.pdf

P. Bourdieu; A. Darbel. (2004). El amor al arte, los museos europeos y su público. Ediciones Paidos Iberica.

Poll, R. (2010). Numeric Statistics for the digitalisation of the European Cultural Heritage. (Program, Ed.) 44(22), 122-131.

Rafael Levenfeld, Valentín Vallhonrat. (2015). El mundo al revés. El calotipo en España. Pamplona: Museo Universidad de Navarra.

Sontag, S. (1996). Sobre la Fotografia. Barcelona: Edhasa.

Valery, P. (1999). Piezas sobre arte. ANTONIO MACHADO.

Villaespesa, E. (2014). Digital Audinece Reserach Report: Understanding Visitors' Motivation and Usage of the Online Collection. London: Tate Digital. 